\title{
Changes on albedo after a large forest fire in Mediterranean ecosystems
}

\author{
Carmen Quintano*a , Alfonso Fernández-Manso ${ }^{\mathrm{b}}$, Victor Fernández-García ${ }^{\mathrm{c}}$, Elena Marcos ${ }^{\mathrm{c}}$, Leonor \\ Calvo ${ }^{\mathrm{c}}$ \\ ${ }^{a}$ Electronic Technology Department, Sustainable Forest Management Research Institute, University \\ of Valladolid-Spanish National Institute for Agricultural and Food Research and Technology (INIA), \\ Francisco Mendizábal, 1, 47014-Valladolid, Spain; ${ }^{\mathrm{b}}$ Agrarian Science and Engineering Department, \\ University of León, Avenida de Astorga s/n, 24400-Ponferrada, Spain; ${ }^{\mathrm{c} A r e a}$ of Ecology, Faculty of \\ Biological and Environmental Sciences, University of León, 24071-León, Spain
}

\begin{abstract}
Fires are one of the main causes of environmental alteration in Mediterranean forest ecosystems. Albedo varies and evolves seasonally based on solar illumination. It is greatly influenced by changes on vegetation: vegetation growth, cutting/planting forests or forest fires. This work analyzes albedo variations due to a large forest fire that occurred on 1921 September 2012 in northwestern Spain. From this area, albedo post-fire images (immediately and 1-year after fire) were generated from Landsat 7 Enhanced Thematic Mapper (ETM+) data. Specifically we considered total shortwave albedo, total-, direct-, and diffuse-visible, and near-infrared albedo. Nine to twelve weeks after fire, 111 field plots were measured (27 unburned plots, 84 burned plots). The relationship between albedo values and thematic class (burned/unburned) was evaluated by one-way analysis of variance. Our results demonstrate that albedo changes were related to burned/unburned variable with statistical significance, indicating the importance of forestry areas as regulators of land surface energy fluxes and revealing the potential of post-fire albedo for assessing burned areas. Future research, however, is needed to evaluate the persistence of albedo changes.
\end{abstract}

Keywords: albedo, Landsat, burned areas, Mediterranean ecosystems, forest fires,

\section{INTRODUCTION}

Forest fires are an annually recurring phenomenon in Mediterranean countries, with an average of 55,500 fires per year in the period 2006-2010 ${ }^{1}$. They have important management and research implications spanning a wide range of scientific disciplines $^{2}$. Traditionally burned areas were mapped by field work, although at present satellite data sensors are widely used to map the extent of affected areas. Numerous remote sensing-based studies ${ }^{3,4,5,6,7}$ have sought to determine the extent of burned area and the long-term effects of fires on ecosystem health.

Moderate to high spatial resolution satellite data, such as provided by Landsat, give the opportunity for detailed spatial mapping of burned areas. Especially, since 2008 when the United States Geological Survey (USGS) started to distribute Landsat data at no charge via the Internet. This provided the opportunity to consider Landsat data for long-term, large area, burned area monitoring ${ }^{6}$. In this frame, it is worth mentioning the U.S. Monitoring Trends in Burn Severity (MTBS) project that is producing annual Landsat derived maps of burned areas and burn severity levels for all the conterminous U.S. and Alaska ${ }^{8}$.

Albedo varies spatially and evolves seasonally based on solar illumination changes, vegetation growth, and human activities such as cutting/planting forests and slash-and-burn agricultural practices ${ }^{9}$. Wildfires can significantly alter albedo by changing the amount of solar radiation absorbed in the climate system ${ }^{10}$. The main post-fire changes in albedo are associated with dissipation of charcoal and ash, and vegetation regrowth. Immediately after a fire event, vegetation loss and surface blackening causes an albedo decrease ${ }^{11,12}$. The long-term effects of biomass burned on albedo can be related to the secondary succession process of forest replacement by croplands and grasslands that have higher albedo ${ }^{13}$.

Most studies relating wildfires and albedo have been done in boreal forests ${ }^{14,15}$ and/or using data from the Moderate

Remote Sensing and Modeling of Ecosystems for Sustainability XII, edited by Wei Gao,

Ni-Bin Chang, Proc. of SPIE Vol. 9610, 961018 • (c) 2015 SPIE

CCC code: $0277-786 X / 15 / \$ 18 \cdot$ doi: $10.1117 / 12.2187346$

Proc. of SPIE Vol. $9610961018-1$ 
Resolution Imaging Spectroradiometer (MODIS). However, albedo change caused by fires varies by ecosystem type ${ }^{13}$. The aim of this study is to analyze the relation between surface after fire and albedo in Mediterranean forest ecosystems (immediately after fire and a summer after fire). To our knowledge, though we found some work relating albedo to burn severity in Mediterranean ecosystems (see ${ }^{16}$ ), this is the first study that propose albedo as a potential indicator of surface burned by a wildfire using Landsat Enhanced Thematic Mapper (ETM+) data and ground measurements.

\section{MATERIAL}

\subsection{Study area}

The study site, 'Castrocontrigo', is located in the Sierra del Teleno, in northwestern Spain (Figure 1). It is a small mountain range with an average slope of $10 \%$ and elevation ranges above sea level between 850 to $2,100 \mathrm{~m}$. The climate is Mediterranean with an average annual rainfall between 650 and $900 \mathrm{~mm}$ and two- three months of dryness in the summer. Soil in this area is very sandy and acidic $(\mathrm{pH}=5.5)$ with low organic matter content ${ }^{17}$. The Third Spanish National Forest Inventory shows that within the fire scar roughly $73 \%$ was covered by Pinus pinaster Ait., $3 \%$ by Pinus nigra Arm., $2 \%$ by Pinus sylvestris L., $7 \%$ by Quercus ilex L., 5\% by Quercus pyrenaica Willd and $10 \%$ by shrubs (Erica australis L., Calluna vulgaris (L.) Hull, Chamaespartium tridentatum (L.) P.E. Gibbs, Halimium alyssoides Lam and Genista florida L.).

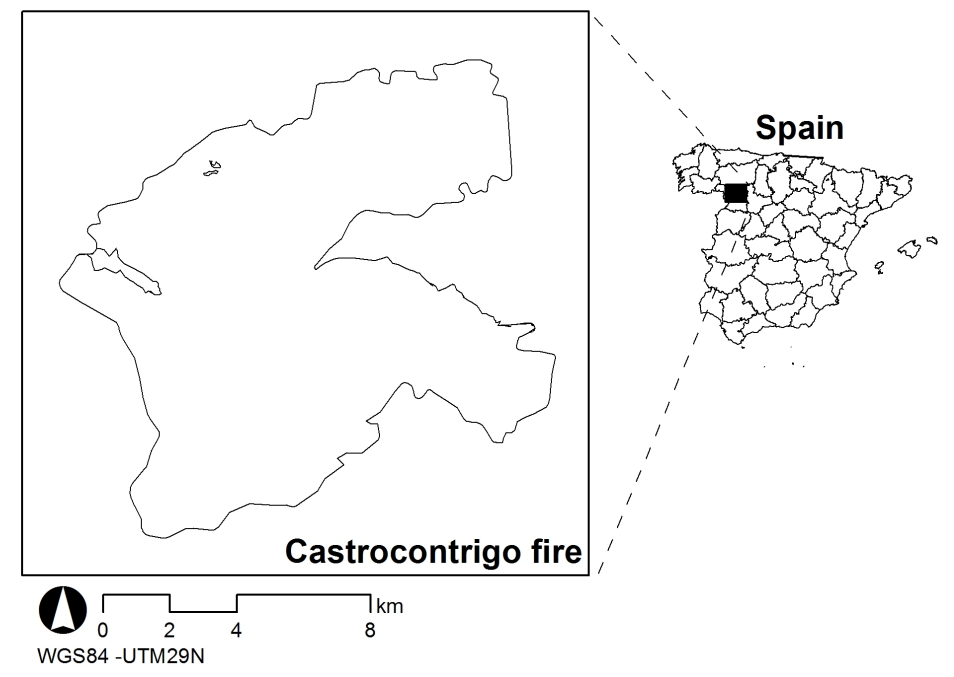

Figure 1. Study area location.

Fires have frequently occurred in this forest ecosystem, generally affecting small areas and mostly caused by dry springsummer storms. However, in August 2012 there was a large fire, which burned $117.75 \mathrm{~km}^{2}$ for three days (between August 19-21, when a heat wave affected the study site). The 2012 spring was drier than usual and the summer was extremely dry (it was the second driest summer in the last 60 years) with an average August precipitation $40 \%$ less than the average value. On the contrary, the fall of 2012 was very humid ( $40 \%$ more than usual). Regarding the initial fire weather conditions, the fire had a Haines Index equal to 6 (maximum value), which shows the high potential contribution of dry, unstable air to the development of the large and erratic plume-dominated fire. Due to the importance of this fire, it was recorded in the Reference Report by the Joint Research Centre of the European Commission: "Forest Fires in Europe, the Middle East and North Africa 2012", as one of the most important large fires at the European level ${ }^{1}$.

\subsection{Datasets}

We used as post-fire data two Landsat 7 Enhanced Thematic Mapper (ETM+) scenes (path/row 203/31), acquired respectively on September 6, 2012, and September 9, 2013, and downloaded from the USGS. We tried to minimize the changes on illumination conditions and their influence on albedo by choosing approximately the same date of acquisition. Fortunately, the forest fire was located in the middle of the Landsat-7 ETM+ scenes and we did not locate any field plot in the affected area by the Scan Line Corrector (SCL) failure. 
We ground measured the thematic variable burned/unburned in 111 field circular-plots ( $30 \mathrm{~m}$ diameter) nine to twelve weeks after fire ( 27 unburned plots, 84 burned plots).

A digital elevation model (DEM) was used to perform the topographic normalization of the Landsat 7 ETM+ images. We utilized the Advanced Spaceborne Thermal Emission and Reflection Radiometer (ASTER) Global Digital Elevation Model Version 2 (GDEM V2) provided by USGS.

\section{METHOD}

As showed in Figure 2, firstly the Landsat $7 \mathrm{ETM}+$ scenes were windowed to the forest fire (latitude / longitude coordinates: upper left corner, $42^{\circ} 20^{\prime} 38.27^{\prime}{ }^{\prime} \mathrm{N} / 6^{\circ} 16^{\prime} 49.51^{\prime}$ ' $\mathrm{W}$; and lower right corner $42^{\circ} 13^{\prime} 59.97 \mathrm{~N} / 6^{\circ} 8^{\prime} 28,40^{\prime \prime} \mathrm{W}$ ). The subset images were topographically normalized and atmospherically corrected using the C-correction algorithm ${ }^{18}$. The reflective bands were scaled to surface reflectance by using the image-based cosine of the solar transmittance (COST) method ${ }^{19}$.

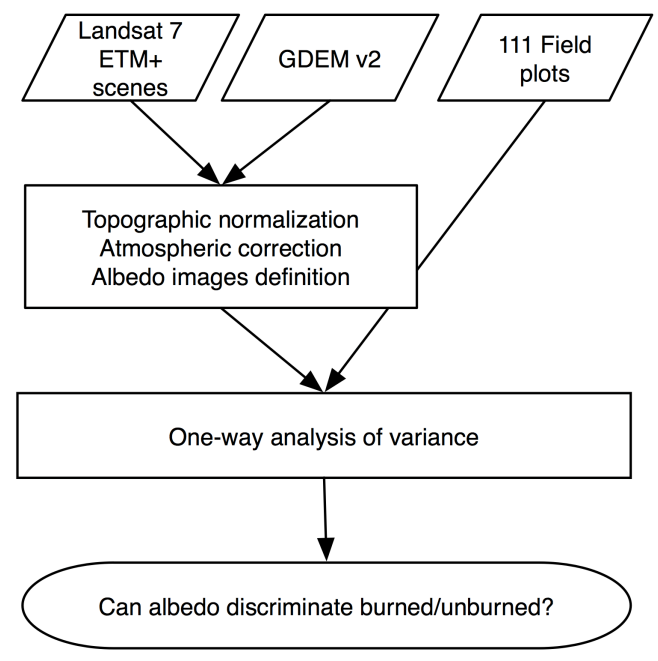

Figure 2. Flowchart methodology.

Next, we used the algorithms to narrowband to broadband conversion of albedo ${ }^{20,21}$ (see equations 1-7). The validation results indicated an excellent agreement between the predictions by these formulae and ground measurements. The average residual error (RSE) of predicted broadband albedos for most sensors including ETM+ was about 0.02 .

$$
\begin{aligned}
& \alpha_{\text {short }}=0.356 \alpha_{1}+0.130 \alpha_{3}+0.373 \alpha_{4}+0.085 \alpha_{5}+0.072 \alpha_{7}-0.0018 \\
& \alpha_{v i s}=0.443 \alpha_{1}+0.317_{2}+0.240 \alpha_{3} \\
& \alpha_{v i s_{-} \text {diffuse }}=0.556 \alpha_{1}+0.281 \alpha_{2}+0.163 \alpha_{3}-0.0014 \\
& \alpha_{\text {vis_direct }}=0.390 \alpha_{1}+0.337_{2}+0.274 \alpha_{3} \\
& \alpha_{\text {NIR }}=0.693 \alpha_{4}+0.212 \alpha_{5}+0.116 \alpha_{7}-0.003 \\
& \alpha_{\text {NIR_diffuse }}=0.864 \alpha_{4}+0.158 \alpha_{7}-0.0043 \\
& \alpha_{\text {NIR_direct }}=0.659 \alpha_{4}+0.342 \alpha_{5}-0.0033
\end{aligned}
$$

where: $\alpha_{\text {short }}$ represents the albedo in the shortwave lengthwaves, $\alpha_{\text {vis }}$ the albedo in the visible lengthwaves, $\alpha_{\text {NIR }}$ the albedo in the near-infrared (NIR) lengthwaves, and $\alpha_{i}$ indicates the albedo in the ' $i$ ' Landsat ETM+ band.

Finally, we applied a mean $3 \times 3$ filter to the albedo images, and extracted the digital values for the field plots surveyed. We used one-way analysis of variance (ANOVA) to check if post-fire albedo allows us to differentiate with statistical significance burned from unburned class. 


\section{RESULTS AND DISCUSSION}

Figure 3 displays the immediately post-fire albedo (shortwave, visible and NIR). From it, we visually notice important differences between burned and unburned areas. Additionally, spatial differences inside of burn perimeter can be visually observed mainly in $\alpha_{\text {NIR }}$.
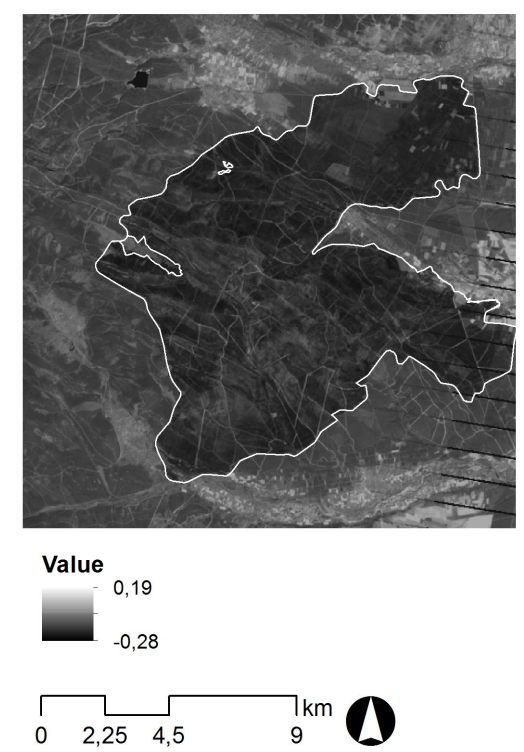
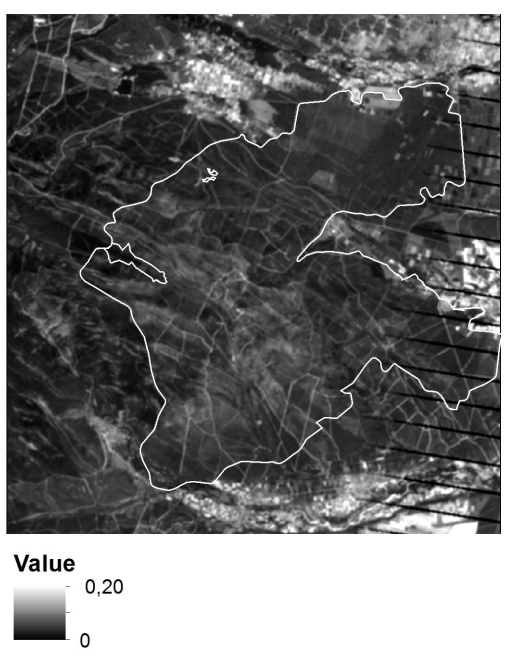
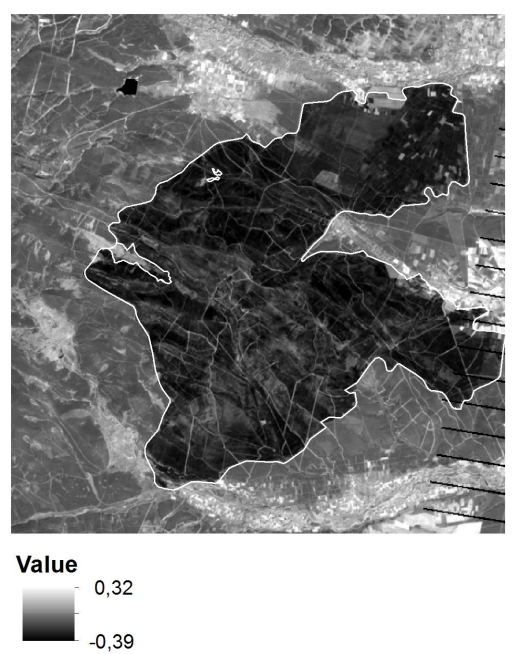

Figure 3. Immediately post-fire albedo: left, shortwave, center, visible, right, near-infrared.

The results of one-way analysis of variance applied to the two post-fire Landsat 7 ETM+ images, September 6, 2012, and September 9, 2013 are shown in Table 1. When considering the immediately after fire image, we observed significant differences $(p$-value $<0.01)$ between the mean albedo value in unburned and burned plots for all considered spectral range (shortwave, visible, and NIR). A year after fire significant differences between burned and unburned values were observed for all albedo images except for $\alpha_{\text {NIR_diffuse }}$, that confused unburned and burned classes $(p$-value $=$ 0.8424). We also observed a decrease of the immediately after fire albedo in shortwave and NIR spectral regions (from 0.1041 to 0.0842 , and from 0.1656 to 0.1068 ) and a little increase of the visible albedo (from 0.0458 to 0.0538 ). A year after fire albedo increased over its pre-fire values in every considered spectral region $(0.1060$ vs. $0.1342,0.0365$ vs. 0.0742 , and 0.1761 vs. 0.1993 ).

Table 1. One-way analysis of variance checking whether there are significant differences between the mean albedo value in unburned and burned area.

\begin{tabular}{|c|c|c|c|c|c|c|c|c|c|c|c|c|c|c|}
\hline \multirow{2}{*}{ Classes } & \multicolumn{2}{|c|}{$\alpha_{\text {short }}$} & \multicolumn{2}{|c|}{$\alpha_{\text {vis }}$} & \multicolumn{2}{|c|}{$\alpha_{\text {vis diffuse }}$} & \multicolumn{2}{|c|}{$\alpha_{\text {vis direct }}$} & \multicolumn{2}{|c|}{$\alpha_{\text {NIR }}$} & \multicolumn{2}{|c|}{$\alpha_{\text {NIR diffuse }}$} & \multicolumn{2}{|c|}{$\alpha_{\text {NIR direct }}$} \\
\hline & $\mu$ & $\begin{array}{c}p- \\
\text { value }\end{array}$ & $\mu$ & $\begin{array}{c}p- \\
\text { value }\end{array}$ & $\mu$ & $\begin{array}{c}p- \\
\text { value }\end{array}$ & $\boldsymbol{\mu}$ & $\begin{array}{c}p- \\
\text { value }\end{array}$ & $\boldsymbol{\mu}$ & $\begin{array}{c}p- \\
\text { value }\end{array}$ & $\mu$ & $\begin{array}{c}p- \\
\text { value }\end{array}$ & $\mu$ & $\begin{array}{c}p- \\
\text { value }\end{array}$ \\
\hline & \multicolumn{14}{|c|}{ Landsat 7 ETM+. September 6. 2012} \\
\hline Unburned & 0.1041 & \multirow{2}{*}{0.0000} & 0.0458 & \multirow{2}{*}{0.0048} & 0.0409 & \multirow{2}{*}{0.0018} & 0.0475 & \multirow{2}{*}{0.0073} & 0.1633 & \multirow{2}{*}{0.0000} & 0.1656 & \multirow{2}{*}{0.0000} & 0.1645 & \multirow{2}{*}{0.0000} \\
\hline Burned & 0.0842 & & 0.0538 & & 0.0493 & & 0.0553 & & 0.1163 & & 0.1068 & & 0.1138 & \\
\hline & \multicolumn{14}{|c|}{ Landsat 7 ETM+. September 9. 2013} \\
\hline Unburned & 0.1060 & \multirow{2}{*}{0.0000} & 0.0365 & \multirow{2}{*}{0.0000} & 0.0314 & \multirow{2}{*}{0.0000} & 0.0383 & \multirow{2}{*}{0.0000} & 0.1761 & \multirow{2}{*}{0.0008} & 0.1823 & \multirow{2}{*}{0.8424} & 0.1772 & \multirow{2}{*}{0.0007} \\
\hline Burned & 0.1342 & & 0.0742 & & 0.0669 & & 0.0770 & & 0.1993 & & 0.1836 & & 0.2014 & \\
\hline
\end{tabular}

$\mu$ : mean value

Immediately after fire, the albedo suffered a decrease of approximately $20 \%$ in shortwave lenghtwaves and $30 \%$ in NIR (Table 2). The visible albedo increased its pre-fire (unburned) values in about $20 \%$. A year after fire, the albedo increased its pre-fire values (unburned plots) in approximately 26\% (shortwave), 105\% (visible) and 13\% NIR. Our results agree with other researchers' findings. On Mediterranean ecosystems. an immediate post-fire shortwave albedo 
decrease was observed after the large fires that burned the Peloponnese peninsula (Greece) in the 2007 summer $^{16}$. This effect had a relatively short duration, as during the first post-fire winter period, which is a period of heavy rainfall in the Mediterranean, most of the char materials were removed by fluvial and aeolian forces. The combination of char removal and regenerating species caused an increase during the next post-fire summer period. The same trend on albedo change was found in a study about albedo and surface temperature evolution after fire ${ }^{22}$. Summer albedo also increases above pre-fire levels because early successional plant functional types, including grasses and deciduous trees and shrubs, have leaves and branches with higher albedo than those of evergreen needle-leaf trees ${ }^{23,24,25}$.

Table 2. Difference between unburned and burned mean albedo values.

\begin{tabular}{|c|c|c|c|c|}
\hline \multirow[t]{2}{*}{ Albedo } & \multicolumn{2}{|c|}{$\begin{array}{c}\mu_{\text {unburned }}-\mu_{\text {burned }} \text { immediately after fire } \\
\text { September } 6.2012\end{array}$} & \multicolumn{2}{|c|}{$\begin{array}{c}\mu_{\text {unburned }}-\mu_{\text {burned }} \text { a year after fire } \\
\text { September } 9.2013\end{array}$} \\
\hline & absolute & relative $(\%)$ & absolute & relative $(\%)$ \\
\hline$\alpha_{\text {short }}$ & 0.0199 & 19.12 & -0.0282 & -26.6 \\
\hline$\alpha_{\text {vis }}$ & -0.0080 & -17.47 & -0.0377 & $-103,29$ \\
\hline$\alpha_{\text {vis diffuse }}$ & -0.0084 & -20.54 & -0.0355 & -113.06 \\
\hline$\alpha_{\text {vis direct }}$ & -0.0078 & $-16,42$ & -0.0387 & -101.04 \\
\hline$\alpha_{\text {NIR }}$ & 0.0470 & 28.78 & -0.0232 & -13.17 \\
\hline$\alpha_{\text {NIR diffuse }}$ & 0.5880 & 35.51 & -0.0013 & -0.71 \\
\hline$\alpha_{\text {NIR direct }}$ & 0.0507 & 30.82 & -0.0242 & -13.66 \\
\hline
\end{tabular}

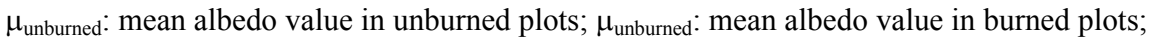

In boreal forest ecosystems, during the first year after fire, summer albedo (shortwave and NIR) decreased substantially below pre-fire levels. In addition, visible albedo remained relatively constant or even increased ${ }^{14}$. Post-fire summer albedo is typically reduced for several years as a consequence of black carbon coatings on soils and the boles of dead trees $^{26}$. The establishment and growth of herbaceous plants, shrubs, and deciduous trees caused rapid increases in summer albedo within the first decade after fire ${ }^{12,24}$.

\section{CONCLUSION}

We evaluated the changes in albedo due to fire in Mediterranean forest ecosystems, considering as study area a large forest fire in north-western Spain. The vegetation state (burned or unburned) was measured in 111 field plots. One-way ANOVA between ground measured vegetation state and albedo (short, visible and NIR), both immediately after fire and a year after fire, showed that burned areas had an albedo value statistically different from unburned areas (with the exception of $\alpha_{\text {NIR diffuse }}$ a year after fire). Immediately post-fire albedo (short and NIR) decrease its value whereas visible albedo increased it. A year after fire albedo increased its value for all considered spectral ranges. These results demonstrate the potential of albedo for assessing burned area in Mediterranean ecosystems. Its performance should be, however, evaluated in other fire regimes and vegetation types.

\section{ACKNOWLEDGMENTS}

The research work was financially supported by the Spanish Ministry of Economy and Competitiveness, and the European Regional Development Fund (ERDF) in the frame of the GESFIRE project "Multi-scale tools for the post-fire management of fire-prone ecosystems in the context of global change" (AGL2013-48189-C2-1-R). The authors would like to thank the Autonomous Government of Castilla and León for sharing their information about the forest fires.

\section{REFERENCES}

[1] Schmuck, G., San-Miguel-Ayanz, J., Camia, A., Durrant, T., Boca, R., Whitmore, C., Liberta', G. and Corti, P., "Forest Fires in Europe, Middle East and Norh Africa", Technical report, Joint Research Centre, (2012).

[2] Holden, Z. A., Smith, A. M. A., Morgan, P., Rollins, M. G., and Gessler, P.E., "Evaluation of novel thermally enhanced spectral indices for mapping fire perimeters and comparisons with fire atlas data," International Journal of Remote Sensing, 26, 4801-4808 (2005). 
[3] Quintano, C., Fernández-Manso, A. and Roberts, D., "Multiple End member Spectral Mixture Analysis (MESMA) to map burn severity levels from Landsat images in Mediterranean countries," Remote Sensing of Environment, 136, 76-88 (2013).

[4] Miller, J. D. and Thode, A.E., "Quantifying burn severity in a heterogeneous land-scape with a relative version of the delta normalized burn ratio (dNBR)," Remote Sensing of Environment, 109, 66-80 (2007).

[5] Cuesta, E. and Quintano, C., "Non-local filtering based pre-classifier to map burned areas in Mediterranean countries," International Journal of Remote Sensing, in press.

[6] Boschetti, L., Roy, D. P., Justice, C. O. and Humber, M. L., "MODIS-Landsat fusion for large area $30 \mathrm{~m}$ burned area mapping," Remote Sensing of Environment, 161, 27-42 (2015).

[7] Padilla, M., Stehman, S. V. and Chuvieco, E., "Validation of the 2008 MODIS-MCD45 global burned area product using stratified random sampling," Remote Sensing of Environment, 144, 187-196 (2014).

[8] Eidenshink, J., Schwind, B., Brewer, K., Zhu, Z., Quayle, B. and Howard, S., “A project for monitoring trends in burn severity," Fire Ecology, 3, 3-21 (2007).

[9] He, T., Liang, S., Wang, D., Wu, H.,Yu, Y., and Wang, J., "Estimation of surface albedo and directional reflectance from Moderate Resolution Imaging Spectroradiometer (MODIS) observations," Remote Sensing of Environment, 119, 286-300 (2012).

[10] O'Halloran, T.L., Law, B.E., Goulden, M.L., Wang, Z., and Barr, J.G., "Radiative forcing of natural forest disturbances," Global Change Biology, 18, 555-65 (2012).

[11] Beringer, J., Hutley, L., Tapper, N., Coutts, A., Kerley, A., and O'Grady, A., "Fire impacts on surface heat, moisture and carbon fluxes from a tropical savanna in northern Australia," International Journal of Wildland Fire, 12, 333-340 (2003).

[12] Lyons, E.A., Jin, Y., and Randerson, J.T., "Changes in surface albedo after fire in boreal forest ecosystems of interior Alaska assessed using MODIS satellite observations," Journal of Geophysical Research, 113, G02012, $1-15(2008)$.

[13] Gatebe, C.K., Ichoku, C.M., Poudyal, R., Román, M.O., and Wilcox, E., "Surface albedo darkening from wildfires in northern sub-Saharan Africa," Environment Research Letters, 9, 065003, 12pp (2014).

[14] Jin, Y., Randerson, J.T., Goetz, S.J., Beck, P.S.A., Loranty, M.M., and Goulden, M.L., "The influence of burn severity on postfire vegetation recovery and albedo change during early sucesión in North American boreal forests," Journal of Geophysical Research-Biogeoscience DOI: 10.1029/2011JG001886 (2012).

[15] Mack, M. C., Treseder, K.K., Manies, K.L., Harden, J.W., Schuur, E.A.G., Vogel, J.G., Randerson, J.T. and Chapin, F.S., "Recovery of aboveground plant biomass and productivity after fire in mesic and dry black spruce forests of interior Alaska," Ecosystems, 11, 209-225 (2008).

[16] Veraverbeke, S., Verstraeten, W.W., Lhermitte, S., Van De Kerchove, R. and Goossens, R., "Assessment of post-fire changes in land surface temperature and surface albedo, and their relation with fire-burn severity using multitemporal MODIS imagery," International Journal of Wildland Fire, 21, 243-256 (2012).

[17] Calvo, L., Santalla, S., Valbuena, L., Marcos, E., Tárrega, R., and Luis-Calabuig E., "Post-fire natural regeneration of a Pinus pinaster forest in NW Spain," Plant Ecology, 197, 81-90 (2008).

[18] Teillet, P. M., Guindon, B., and Goodenough, D.G., "On the slope-aspect correction of multispectral scanner data," Canadian Journal of Remote Sensing, 8, 84-106 (1982).

[19] Chavez, P. S. Jr., "Image-based atmospheric corrections - Revisited and improved," Photogrammetric Engineering and Remote Sensing, 62, 1025-1036 (1996).

[20] Liang, S., "Narrowband to broadband conversions of land surface albedo. I Algorithms," Remote Sensing of Environment, 76, 213-238 (2000).

[21]Liang, S., Shuey, C.J., Russ, A.L., Fang, H., Chen, M., Walthall, C.L., Daughtry, C.S.T., and Hunt Jr., R., "Narrowband to broadband conversions of land surface albedo: II. Validation," Remote Sensing of Environment, 84, 25-41 (2002).

[22] Franch, B., and Sobrino, J.A., "Evolución del albedo en Europa e influencia en la temperatura (Albedo evolution in Europe and influence on temperature)," Spanish Journal of Remote Sensing, 39, 22-33 (2013).

[23] Amiro, B.D., Orchansky, A.L., Barr, A.G., Black, T.A., Chambers, S.D., Chapin III, F.S., Goulden, M.L., Litvak, M., Liu, H.P., McCaughey, J.H., McMillan, A., and Randerson, J.T., "The effect of postfire stand age on the boreal forest energy balance," Agricultural and Forest Meteorology, 140(1-4), 41-50 (2006).

[24] McMillan, A. M. S., and Goulden, M.L., "Age-dependent variation in the biophysical properties of boreal forests," Global Biogeochemical Cycles, 22, GB2023 (2008). 
[25] Roberts, D.A., Ustin, S.L., Ogunjemiyo, S., Greenberg, J., Dobrowski, S.Z., Chen, J.Q., and Hinckley, T.M., "Spectral and structural measures of northwest forest vegetation at leaf to landscape scales," Ecosystems, 7, 545-562 (2004).

[26] Chambers, S. D., and Chapin III, F.S., "Fire effects on surface atmosphere energy exchange in Alaskan black spruce ecosystems: Implications for feedbacks to regional climate," Journal of Geophysical Research, 107, 8145 (2002). 